\title{
LINC01255 combined with BMI1 to regulate Human Mesenchymal Stromal Senescence and Acute myeloid leukemia cell proliferation through repress the transcription of MCP-1
}

\section{Qinghua Liu}

The Second Affiliated Hospital of Shandong First Medical University https://orcid.org/0000-00018468-4718 Jing Dong

The Second Affiliated Hospital of Shandong First Medical University Jie Li

The Second Affiliated Hospital of Shandong First Medical University

\section{Yanchao Duan}

The Second Affiliated Hospital of Shandong First Medical University

\section{Keqiang Wang}

The Second Affiliated Hospital of Shandong First Medical University

\section{Qiuhong Kong}

The Second Affiliated Hospital of Shandong First Medical University

Hong Zhang ( $\nabla$ tyfyzhh@163.com )

The Second Affiliated Hospital of Shandong First Medical University

\section{Primary research}

Keywords:

Posted Date: May 13th, 2020

DOl: https://doi.org/10.21203/rs.3.rs-25878/v1

License: (c) (i) This work is licensed under a Creative Commons Attribution 4.0 International License. Read Full License 


\section{LINC01255 combined with BMI1 to regulate Human Mesenchymal Stromal Senescence and Acute myeloid leukemia cell proliferation through repress the transcription of MCP-1}

Qinghua Liu ${ }^{1 \#}$, Jing Dong ${ }^{2}, \mathrm{Jie} \mathrm{Li}^{2}$, Yanchao Duan ${ }^{2}$, Keqiang Wang ${ }^{3}$, Qiuhong Kong ${ }^{2}$, Hong Zhang ${ }^{2 \# *}$.

${ }^{1}$ Clinical Laboratory, The Second Affiliated Hospital of Shandong First Medical University, Taian, Shandong, China.

${ }^{2}$ Department of Hematology, The Second Affiliated Hospital of Shandong First Medical University, Taian, Shandong, China.

${ }^{3}$ Research Service Office, The Second Affiliated Hospital of Shandong First Medical University, Taian, Shandong, China.

\# These authors contributed equally: Qinghua Liu, Hong Zhang.

*Correspondence: Hong Zhang

Department of Hematology

The Second Affiliated Hospital of Shandong First Medical

University

The Second Affiliated Hospital

No. 706, Taishan Street,

Taian, 271000, Shandong, China

Tel.: 86-0638-6236422

E-mail: kqhllx@163.com 


\section{ABSTRACT:}

Background: Long non-coding RNAs (lncRNAs) govern fundamental biochemical and cellular biology processes, for example, participate in chromatin remodeling, imprinting, splicing, transcriptional regulation and translation. Dysregulation of lncRNA expression is act as a feature of various diseases and cancers, including hematopoietic malignancies. However, the clinical relevance of myelodysplastic syndrome (MDS) and acute myeloid leukemia preceded by MDS (MDS-AML) requires further research. Recently, IncRNAs have been demonstrated plays an important role in hematopoiesis, thus, to further finding more functional lncRNA seemed particularly important.

Methods: Western blotting, real-time PCR, RNA-pulldown, RIP, Chromatin immunoprecipitation (ChIP), cellular compartments extraction assays, SA- $\beta$-gal staining, lentivirus transfection, cell viability assay and cell proliferation assays were used to examine the relationship between lncRNA LINC01255 and its regulation of p53-p21 pathway in human mesenchymal stromal and acute myeloid leukemia cells.

Results: LncRNA LINC01255 is highly expressed in bone marrow cells of AML patients, CD34+ cells of MDS-AML patients and AML cell lines and the higher expression of LINC01255 is assocoated with poor survival rate of AML patients. LINC01255 can interact with BMI1 and repress the transcription of MCP-1 to active p53-p21 pathway, thus inhibiting the senescence of human mesenchymal stromal and proliferation of acute myeloid leukemia cell. 
Conclusions: We discovered a novel functional lncRNA LINC01255, which can regulate the senescence of human mesenchymal stromal and the proliferation of acute myeloid leukemia cell through inhibiting the transcription of MCP-1. 


\section{BACKGROUND}

Myelodysplastic syndromes (MDS) is a group of ineffective hematopoiesis hemopathies disorders characterized by defects in differentiation of hematopoietic precursor and amplification of the abnormal clones [1-4]. MDS is usually a rare group of "bone marrow failure disorder" that is not recognized and diagnosed. Their hematopoietic stem cells may be immature and accumulate in bone marrow with shortened life span, resulting in fewer mature blood cells in the hematopoietic system than normal people and lower organism healthy. However, although mature cells cannot be produced in bone marrow, MDS is not necessarily a terminal disease. Several MDS patients will have a decrease in blood cells and/or platelets gradually losing the body's ability to resist infection and control bleeding. In addition, approximately $30 \%$ of MDS patients with this type of bone marrow failure syndrome will progress to acute myeloid leukemia (AML) [5]. Recently, some prognostic prediction models have been developed to better stratify the risk of MDS and AML patients, such as the international prognostic scoring system (IPSS) the revised IPSS (IPSS-R) for MDS [6-9] and the European Leukemia Net (ELN) risk classification for AML [10]. Nevertheless, even in the same risk groups, the prognosis of patients may be different [11-13]. Although several approved drug treatment strategies can be used to help treat the symptoms and slow the progression of the disease, they are not appropriate for all MDS patients. Therefore, it is more important to find more functional biomarkers and therapeutic targets for MDS and AML.

In recent years, as an increasingly important method, high-throughput transcriptome analysis uncovers transcription states of genomic. About $75 \%$ of genome can be transcribed into RNAs, of which few are transcribed and tanslated into proteins, and others are transcribed as noncoding RNAs (ncRNAs) [14]. According to the length, ncRNAs can be divided into shorter than 200 bp RNAs, such as microRNAs (miRNAs), housekeeping ncRNAs, PIWI-interacting RNAs (piRNAs), small interfering RNA (siRNAs), small nuclear RNAs (snRNAs), and small nucleolar RNAs 
(snoRNAs) and longer than 200 bp RNAs, contains the long non-coding RNAs (lncRNAs) [15, 16]. LncRNAs are generally transcribed in genome and govern fundamental biochemical and cellular processes, for example, participate in chromatin remodeling, imprinting, splicing, transcriptional regulation and translation [17]. As well, lncRNAs have been demonstrated plays an important role in hematopoiesis [18, 19]. For example, during myeloid differentiation and maturation, HOTAIRM1 and NEAT1 are highly expressed and play key roles in this progress [18]. Xist located in $\mathrm{X}$ chromosome inactivates $\mathrm{X}$ chromosome of female cells, and female mice with Xist deleted can develop into a highly aggressive disease mimicking MDS/MPN [20]. MEG3 functions as a scaffold for the transcription regulation complex PRC2, and has been associated with multiple human malignancies, such as MDS and AML [21, 22]. Consistently, up to now, the functional lncRNAs relate to MDS and AML need more deeply research.

B Lymphoma Mo-MLV Insertion Region 1 (BMI1) is a member of the polycomb group of transcriptional repressor genes, expressed in stem cells, progenitors and many cancer cells, in which it regulates self-renewing proliferation, apoptosis and invasion [23-27]. In recent studies, BMI1 is highly expressed in $\mathrm{CD}^{+} 4^{+}$cells of MDS-AML patients and is considered to be a novel molecular biomarker of MDS. In addition, BMI1 can bind to the promoter of MCP-1 to inhibit its expression and reduce the activity of SA- $\beta$-gal and p53-p21 signaling pathways in senescence early phase of umbilical cord blood-derived MSCs (UCB-MSCs) proliferating in vitro [28-30].

In this report, we found a novel functional lncRNAs LINC01255, which is highly expressed in AML patients bone marrow cells, MDS-AML patients CD34 ${ }^{+}$cells and AML cell lines, and can interact with BMI-1 to repress the transcription of MCP-1 thereby activating the activation of p53-p21 pathway. In addition, LINC01255 can inhibit the senescence of human mesenchymal stromal and the proliferation of acute myeloid leukemia cells through inhibiting expression of MCP-1 combined with BMI1. 


\section{METHODS}

\section{Antibodies and Reagents}

The sources of antibodies against the following proteins were: $\beta$-actin (A1978, 1:10,000 for WB) from Sigma; BMI1 (A0147, 1:1,000 for WB), Lamin B1 (A11495, 1:1000 for WB), MCP-1 (A7277, 1:1,000 for WB), p-p52-s392 (AP1137, 1:1,000 for WB) and $\mathrm{p} 21$ (A1483, 1:1,000 for WB) from ABclonal. RNA polymerase II (ab264350, 1:200 for ChIP), H3K4me3 (ab8580, 1:200 for ChIP) and H2AK119Ub (ab195467, 1:200 for ChIP) from abcam.

\section{Plasmids}

lncRNA LINC01255 was carried by pcDNA3.1 vector. FLAG-BMI1 was carried by pLenti-Hygro vector.

\section{Cell Culture}

KG1, OCI-AML2, OCI-AML3 and OCI-AML5 were got from the American Type Culture Collection (Manassas, VA) and cultured under the manufacturer's instructions. UCB-MSC cell was collected from umbilical veins after neonatal delivery under maternal informed consent fails (Supplementary Data 1). UCB was harvests and separated within $24 \mathrm{~h}$ of collection. Cultures were maintained at $37^{\circ} \mathrm{C}$ with $21 \% \mathrm{O} 2$ and 5\% CO2 in culture medium with changed twice a week. All of the cultured cells were authenticated by examination of morphology and growth characteristics, and were confirmed to be mycoplasma-free.

\section{Western Blotting}

Cells were lysed by RIPA buffer, and re-suspending in $5 \times$ SDS-PAGE loading buffer. The boiled protein samples were then subjected to sodium dodecyl sulfate polyacrylamide gel electrophoresis (SDS-PAGE) and transferred to nitrocellulose membrane incubated with appropriately primary antibodies and secondary antibodies, then imaging under imager WBS2000. 


\section{RNA-pulldown and Silver Staining}

The RNA pull-down assay was modified from previous studies [52]. Substrate RNAs were in vitro transcribed in a $100 \mu$ reaction mix containing $1 \mu \mathrm{g}$ of pcDNA3.1-LINC01255 DNA detailed protocol as RiboMAX ${ }^{\mathrm{TM}}$ Large Scale RNA Production Systems-T7 manufacturer's instructions (P1300, Promega). In addition, transcribed RNAs produced 3' End Desthiobiotinylation using Pierce ${ }^{\mathrm{TM}}$ RNA 3' End Desthiobiotinylation Kit (20163, Invitrogen) and incubated with cell lysis for RNA-pulldown assays as Pierce ${ }^{\mathrm{TM}}$ Magnetic RNA-Protein Pull-Down Kit (20164, Invitrogen). Then, the eluents were collected and visualized on NuPAGE 4-12\% Bis-Tris gel (NP0321BOX, Invitrogen) followed by silver staining with silver staining kit (24600, Invitrogen). The distinct protein bands were retrieved and analyzed by LC-MS/MS.

\section{Mass spectrometry (MS) analysis.}

lncRNA LINC01255 interacted proteins performed LC-MS/MS analyzed by Thermo Finnigan LTQ linear ion trap mass spectrometer (Thermo Fisher Corporation, San Jose, CA) in line with a Thermo Finnigan Surveyor MS Pump Plus HPLC system. The mass spectrometry analysis was carried out in a data-dependent mode with an automatic switch between a full MS and an MS/MS scan in the obitrap. Peptide sequences were searched using trypsin specificity and allowing a maximum of two missed cleavages. Sequest was searched with a peptide tolerance of $3.0 \mathrm{Da}$ and a fragment ion tolerance of 1.0 Da. The results of peptide sequences information of LINC01255 interact proteins were offered in Supplemental Table 1.

\section{RNA immunoprecipitation (RIP).}

For KG1 cells, $1 \times 10^{7}$ cells were harvested and crosslinked with $0.3 \%$ formaldehyde for $10 \mathrm{~min}$ at RT and quenched with $0.125 \mathrm{M}$ glycine for $5 \mathrm{~min}$. Nuclei were extracted and lysed in RIP Cross-Linked Lysis Buffer and product protocol supplied by Magna Nuclear RIPTM (Cross-Linked) Nuclear RNA-Binding Protein Immunoprecipitation 
Kit (17-10520, Millipore). In addition, RNAs were extracted with TRIzol and detected by qRT-PCR.

\section{Chromatin immunoprecipitation (ChIP)}

ChIP experiments were performed according to the procedure described previously $[31,32]$. About $1 \times 10^{7}$ cells were cross-linked and quenched with $1 \%$ formaldehyde and $125 \mathrm{mM}$ glycine. The fixed cells were resuspended in SDS lysis buffer and sonicated to generate chromatin fragments of 250-500bp. Then the sonicated lysis were immuneprecipitated with indicated antibodies, and analyzed with qRT-PCR.

\section{qRT-PCR}

Total cellular RNAs were isolated by TRIzol reagent (Invitrogen) and transcribed by the Reverse Transcription System (Roche). Quantitation of all gene transcripts was done by qPCR using a Power SYBR Green PCR Master Mix (Roche) and Q5 detection system (Thermo) with the expression of ACTB as the internal control. The primers used were listed in Supplementary Data 2.

\section{RNA Interference}

In our studies, the short hairpin RNAs (shRNAs) against LINC01255, BMI1 or MCP-1 were expressed as lentiviral, purchased from GenePharma, transfected into appropriate cells. The sequences of shRNAs are provided in Supplementary Data 3.

\section{SA- $\beta$-gal staining}

SA- $\beta$-gal staining was used as a biomarker of senescence in UCB-MSCs. SA- $\beta$-gal activity was qualitatively assessed with a senescence cells histochemical staining kit (CS0030; Sigma) according to the manufacturer's instructions.

\section{Cell Viability Assay}

Indicated cells were cultured in appropriate media for $24 \mathrm{~h}$ in 96-well plates, add $10 \mu \mathrm{l}$ CCK-8 regents ahead of 2-4 hours for test OD value of $450 \mathrm{~nm}$. The detail protocols 
were supplied by Cell Counting Kit-8 (HY-K0301-500T, MedChem Express).

\section{Statistical Analysis}

All of experimental data from biological triplicate experiments are presented with error bar as mean \pm S.D. and two-tailed unpaired Student's t-test was used for comparing two groups of data. Analysis of variance (ANOVA) with Bonferroni's correction was used to compare multiple groups of data. A P value of less than 0.05 was considered significant and higher than 0.05 was considered no specific differences. All of the statistical testing results were determined by SPSS 22.0 software diagrams were conducted by GraphPad prism 8.0. Before statistical analysis, variation within each group of data and the assumptions of the tests were checked.

\section{Data Availability}

All relevant data are available from the authors on request. 


\section{RESULTS}

\section{LncRNA LINC01255 is highly-expressed in AML patients bone marrow cells, MDS-AML patients $\mathrm{CD34}^{+}$cells and AML cell lines.}

LncRNAs regulate basic biochemical and cellular biology processes and play important role in regulating development, cell differentiation, proliferation and apoptosis of hematopoiesis and cancer cells [33]. In recent report, we compared the expression profile of lncRNA by comparing 6 patients with AML and 6 healthy controls. The analysis of the volcano graph with 2 fold change cut-off found that there were 1011 lncRNA specific expression disorders, including 562 upregulated lncRNAs and 449 downregulated lncRNAs, respectively [34]. After further analysis, we found that LINC01255 is one of highly expressed lncRNAs in AML patients. In order to further validate this, we detected the expression of LINC01255 in bone marrow cells of AML patients and compared it with healthy control group. As shown in Figure 1A, lncRNA LINC01255 is highly-expressed in bone marrow cells of AML patient and has a positive correlation with the poor prognosis of AML patients (Figure 1B). For the reason of the disease of MDS patients may develop into AML, we detected the expression of LINC01255 in $\mathrm{CD}^{+} 4^{+}$cells of MDS patients. The results show that LINC01255 is highly expressing in $\mathrm{CD}^{+} 4^{+}$cells of MDS patients (Figure 1C). To further explore the function of LINC01255, we detected the expression levels in AML cell lines and normal bone marrow cells, such as KG1, OCI-AML2, OCI-AML3 and OCI-AML5. The results show that LINC01255 is highly expressed in AML cell lines (Figure 1D), these results suggest that LINC01255 may play a role in AML cell.

\section{LINC01255 is physically associated with BMI1}

To better understand the mechanistic role of lncRNA LINC01255 in AML cells, we employed RNA pull-down assays through incubate LINC01255, transcribed in vitro, together with KG1 cell lysates, then, conduct mass spectrometry (MS) to analysis potential LINC01255 associated proteins. After analysis we identified BMI1 as a possible LINC01255-interacting protein (Figure 2A). Furthermore, we performed 
RNA pull-down assays and followed by western blotting assays, and immunoblotting with BMI1 antibody in KG1 cells (Figure 2B), the results showing that LINC01255 could interact with BMI1. In another way, we employed an RNA immunoprecipitation (RIP) assays with anti-BMI1 antibody and followed by qRT-PCR assays (Figure 2C), these results further validated the interaction between lncRNA LINC01255 and BMI1.

To confirm the interaction between lncRNA LINC01255 and BMI1, we employed another RNA pull-down assay and RIP assays in OCI-AML3 cells, which indicates that the interaction between LINC01255 and BMI1 is prevalent in AML cell lines (Figure 2D). In addition, we performed RIP assays to detect the interaction between LINC01255 and BMI1 in different cellular compartments of KG1 cells, the results indicated that BMI1 could interact with LINC01255 in nuclear but not cytosolic (Figure 2E), which is more likely to depend on the nuclear location of LINC01255 (Figure 2F). In conclusion, LINC01255 could interact with BMI1 and the nuclear location characteristics of LINC01255 indicate that it has a transcription functions combined with BMI1.

\section{LINC01255 associated with BMI1 to repress the transcription of MCP-1}

As a transcriptional repressor, BMI1 could prevent the premature activation of senescence associated genes, including INK4a, ARF and MCP-1 during senescence process $[35,36]$. In order to further explore the function of LINC01255, we examined the expression of LINC01255 in early and late stage of UCB-MSC senescence, the results showing that the expression of LINC01255 is significantly decreased in senescent late stage of UCB-MSC cells (Figure 3A). In previous studies, BMI1 could bind to the promoter of MCP-1 to repress the expression of MCP-1, we detected the binding of BMI1 to the MCP-1 locus in early stage of UCB-MSC senescence in the absence of RNAse or not. The result indicated that RNAse could significantly decrease the binding of BMI to MCP-1 locus in senescence early stage of UCB-MSC cells and KG1 cells (Figure 3B) analyzed by qChIP assays. In addition, we transfected shRNA plasmids targeting BMI1 into KG1 cells, and the expression of 
BMI1 is reduced, as shown in Figure 3C. In addition, we performed qChIP analysis and the results showed that knockdown BMI1 significantly decreased the monoubiquitination modification at lysine 119 of histone2A (H2AK119Ub) (Figure 3D) and increased the trimethylation modification at lysine 4 of histone 3 (H3K4me3) and localization of polymerase II at the promoter regions of MCP-1 (Figure 3E). In thus, the above results indicate that BMI1 binding to the promoter regions of MCP-1 may be regulated by functional RNAs.

Furthermore, in order to character the function of LINC01255 binding to BMI1, we transfected shRNAs plasmids target LINC01255 into KG1 cells to reduce its expression (Figure 3F). Then, we detect the binding of BMI1 to the promoter of MCP-1, and the results showed that reducing the expression of LINC01255 significantly decreased the enrichment of BMI1 at the MCP-1 locus (Figure 3G), simultaneously, the expression of MCP-1 was increased in senescent early stage of UCB-MSC cells and KG1 cells.(Figure 3H). In conclusion, LINC01255 may repress the transcription of MCP-1 combined with BMI1 in UBC-MSC and AML cell lines.

\section{Down-regulation of LINC01255 active the p53-p21 signaling pathway through enhancing MCP-1 expression}

In previous studies, MCP-1 is a 'trigger factor' of ROS-p38-MAPK-p53/p21 signaling cascade. MCP-1, as a component of senescence-associated secretory phenotype (SASP) during expansion of UCB-MSCs, can activate the p53-p21 signaling cascade and increase the protein level of Ser392 phosphorylated p53 and the total expression of p21 [37]. To better understand the relationship between LINC01255 and p53-p21 signaling pathway, we detected the expression of p53 phosphorylated at Ser392 and the total expression of p21 under knockdown of LINC01255 in senescent early stage of UCB-MSC cells, and the result showed that knocking down LINC01255 can increase the activity of p53-p21 pathway by increasing the expression of p53 phosphorylation at Ser392 and the total expression of p21 (Figure 4A). In addition, knockdown of LINC01255 could also increase the activity of SA- $\beta$-gal (Figure 4B). 
Also, knockdown of LINC01255 could increase the activity of p53-p21 pathway in KG1 cells (Figure 4A). While, knocking down BMI1 could also increase the activity of p53-p21 pathway in KG1 cells (Figure4C). Interestingly, the increased activity of p53-p21 pathway due to knockdown of LINC01255 could be reversed by overexpression of BMI1 (Figure 4D). Overexpression BMI1 could inhibit the transcription of MCP-1 through binding to the promoter of MCP-1 and this inhibition could rescue by knockdown LINC01255 in some extent analyzed by qChIP against H3K4me3 and polymerse II antibodies (Figure 4E). Under these results, we detected that the increased activity of p53-p21 pathway under down-regulation of LINC01255 may be related to the increased expression of MCP-1. To prove this hypothesis, we examined the expression of p53 phosphorylated at Ser392 and the total expression of p21 under knockdown LINC01255, the increased activity of p53-p21 signaling could obliterated by knockdown of MCP-1 through special shRNAs (Figure 4F).

\section{BMI1/LINC01255 axis regulate senescence of MSC and proliferation of AML} cells

In a recent report, MCP-1 was identified as a crucial component of the SASP in human UCB-MSC senescence process, the secretion of MCP-1 was inhibited by BMI1 in the early stage, and increased along with senescence. During this process, the expression of BMI1 was decreased [37]. According to our previous results, the expression of LINC01255 is decreased in late stage of UCB-MSC senescence (Figure 3A). Then, we asked whether downregulated LINC01255 could affect the senescence of human mesenchymal stromal cells (MSC). Therefore, we transfected the shRNAs target for LINC01255 into UCB-MSC cells and the result showed that knocking down LINC01255 increased SA- $\beta$-gal activity (Figure 5A) and accelerated the senescence of UCB-MSC (Figure 5B). To further exploring the function of LINC01255 in AML cells, we detected the cell growth ability of KG1 cells by CCK8 assays (Figure 5C) and growth examination experiments (Figure 5D) and the results indicated that down-regulation of LINC01255 could accelerate the proliferation of KG1 cells, but this acceleration will be braked by overexpressing BMI1. 


\section{DISCUSSION}

In this study, we discovered a new functional lncRNA LINC01255, which is highly expressed in AML patient bone marrow cells, MDS-AML patient $\mathrm{CD}_{3} 4^{+}$cells and AML cell lines, and combined with BMI1 to regulate the senescence of UCB-MSCs and proliferation of KG1 cells through affecting p53-p21 signaling activity related to MCP-1.

In previous studies, BMI1 is a transcriptional repressor and plays an essential roles in the maintenance of appropriate gene expression, while, BMI1 deletion could repress the proliferative and self-renewal of HSC through INK4A/ARF pathway [38-40]. In addition, the expansion and self-renewal of primary leukemic AML CD34 ${ }^{+}$cells dependent on BMI1 repress cell cycle regulators, p16 and p19/p14. However, whether LINC01255 is participated in the regulation of p16 and p19/14 combined with BMI1 in leukemic AML CD34 ${ }^{+}$is not clear. While, our data show that LINC01255 is highly expressed in AML patient $\mathrm{CD}^{+} 4^{+}$and can interact with BMI1 to regulate the proliferation of AML cell lines, therefore, LINC01255 may have the function of regulating the self-renewal of leukemic AML CD34 ${ }^{+}$. In MDS and MDS-AML patients, BMI1 is required to regulate the self-renewal in $\mathrm{CD} 34^{+}$cells and it might be a novel biomarker for disease progression and prognosis in these patients, and highly expressed of LINC01255 might provide a new diagnostic approaches [27].

The monocyte chemoattractant protein-1 (MCP-1/CCL2) is a member of the C-C chemokine family, and a potent chemotactic factor for monocytes. It is also expressed in tumor cells, B-ALL, AML cells and tumor stroma cells, which are mainly secreted by inflammatory cells and endothelial cells [41-44]. MCP-1 is associated with a poor prognosis in patient with certain cancers, such as breast cancer. Also, MCP-1 can promote lung metastasis or glioblastoma and tumor growth [41]. In addition, MCP-1 is associated with senescence of UCB-MSC through activating p53/p21 signaling pathway. In our results, lncRNA LINC01255 could interact with BMI1 and repress the 
expression of MCP-1 in UCB-MSC and AML cell lines. However, in some case, highly secreted MCP-1 could not promote the proliferation of KG1 and it was not originate from AML cells of MDS-AML patients, it might be secreted by inflammatory or endothelial cells $[45,46]$.

\section{CONCLUSIONS}

In our study, we found a new functional lncRNA LINC01255, which is highly expressed in UCB-MSC, MDS-AML patients $\mathrm{CD}^{+}$cells and AML cells. Interestingly, LINC01255 can interact with BMI1 to repress the expression of MCP-1 and active p53-p21 signaling pathway in UCB-MSC and AML cells. In thus, this novel functional lncRNA may provide a new therapeutic approach for MDS-AML or related diseases.

\section{ABBREVIATIONS}

MDS: Myelodysplastic syndromes; AML: Acute myeloid leukemia; IPSS : International prognostic scoring system; IPSS-R: international prognostic scoring system (IPSS) the revised IPSS; ELN : European Leukemia Net; ncRNAs : noncoding RNAs; miRNAs: microRNAs; piRNAs : PIWI-interacting RNAs; siRNAs : small interfering RNA; snRNAs : small nuclear RNAs; snoRNAs : small nucleolar RNAs; lncRNAs : long non-coding RNAs; BMI1: B Lymphoma Mo-MLV Insertion Region 1; UCB-MSCs : Umbilical cord blood-derived MSCs; RIP : RNA immunoprecipitation; SASP : Senescence-associated secretory phenotype; MSC : Human mesenchymal stromal cells.

\section{DECLARATIONS}

\section{Ethics approval and consent to participate}

Ethics approval and consent files were offered in Ethics approval file.

\section{Availability of data and materials}

Not applicable 


\section{Author contributions}

Hong Zhang conceived this project; Qinghua Liu, Hong Zhang, Jing Dong, Jie Li, Yanchao Duan, Keqiang Wang and Qiuhong Kong conducted experiments; Qinghua Liu and Hong Zhang acquired and analysed data; Hong Zhang wrote the manuscript.

\section{Funding}

This study was supported by Medical and Health Science and Technology Development Project of Shandong (2018WS122), Science and Technology Development Plan (guidance plan) of Taian (2018NS0123), 2019-2020 Chinese Medicine Science and Technology Development Project of Shandong (2019-0343).

\section{Acknowledgements}

Not applicable.

\section{Consent for publication}

Not applicable.

\section{Conflict of interest}

The authors have declared that no conflict of interest exists. 


\section{REFERENCES}

1. Arber DA, Orazi A, Hasserjian R, Thiele J, Borowitz MJ, Le Beau MM, Bloomfield CD, Cazzola M, Vardiman JW: The 2016 revision to the World Health Organization classification of myeloid neoplasms and acute leukemia. Blood 2016, 127(20):2391-2405.

2. Zhao X, Yin H, Li N, Zhu Y, Shen W, Qian S, He G, Li J, Wang X: An Integrated Regulatory Network Based on Comprehensive Analysis of mRNA Expression, Gene Methylation and Expression of Long Non-coding RNAs (IncRNAs) in Myelodysplastic Syndromes. Front Oncol 2019, 9:200.

3. Huang HH, Chen FY, Chou WC, Hou HA, Ko BS, Lin CT, Tang JL, Li CC, Yao M, Tsay W et al: Long non-coding RNA HOXB-AS3 promotes myeloid cell proliferation and its higher expression is an adverse prognostic marker in patients with acute myeloid leukemia and myelodysplastic syndrome. BMC Cancer 2019, 19(1):617.

4. Larsson CA, Cote G, Quintas-Cardama A: The changing mutational landscape of acute myeloid leukemia and myelodysplastic syndrome. Mol Cancer Res 2013, 11(8):815-827.

5. Zeidan AM, Wang R, Davidoff AJ, Ma S, Zhao Y, Gore SD, Gross CP, Ma X: Disease-related costs of care and survival among Medicare-enrolled patients with myelodysplastic syndromes. Cancer 2016, 122(10):1598-1607.

6. Greenberg P, Cox C, LeBeau MM, Fenaux P, Morel P, Sanz G, Sanz M, Vallespi T, Hamblin T, Oscier $\mathrm{D}$ et al: International scoring system for evaluating prognosis in myelodysplastic syndromes. Blood 1997, 89(6):2079-2088.

7. Voso MT, Fenu S, Latagliata R, Buccisano F, Piciocchi A, Aloe-Spiriti MA, Breccia M, Criscuolo M, Andriani A, Mancini S et al: Revised International Prognostic Scoring System (IPSS) predicts survival and leukemic evolution of myelodysplastic syndromes significantly better than IPSS and WHO Prognostic Scoring System: validation by the Gruppo Romano Mielodisplasie Italian Regional Database. J Clin Oncol 2013, 31(21):2671-2677.

8. Della Porta MG, Tuechler H, Malcovati L, Schanz J, Sanz G, Garcia-Manero G, Sole F, Bennett JM, Bowen D, Fenaux P et al: Validation of WHO classification-based Prognostic Scoring System (WPSS) for myelodysplastic syndromes and comparison with the revised International Prognostic Scoring System (IPSS-R). A study of the International Working Group for Prognosis in Myelodysplasia (IWG-PM). Leukemia 2015, 29(7):1502-1513.

9. de Swart L, Smith A, Johnston TW, Haase D, Droste J, Fenaux P, Symeonidis A, Sanz G, Hellstrom-Lindberg $\mathrm{E}$, Cermak J et al: Validation of the revised international prognostic scoring system (IPSS-R) in patients with lower-risk myelodysplastic syndromes: a report from the prospective European LeukaemiaNet MDS (EUMDS) registry. Br J Haematol 2015, 170(3):372-383.

10. Dohner H, Estey E, Grimwade D, Amadori S, Appelbaum FR, Buchner T, Dombret H, Ebert BL, Fenaux $\mathrm{P}$, Larson RA et al: Diagnosis and management of AML in adults: 2017 ELN recommendations from an international expert panel. Blood 2017, 129(4):424-447.

11. Estey E: Acute myeloid leukemia: 2016 Update on risk-stratification and management. Am J Hematol 2016, 91(8):824-846.

12. Hou HA, Tsai CH, Lin CC, Chou WC, Kuo YY, Liu CY, Tseng MH, Peng YL, Liu MC, Liu CW et al: Incorporation of mutations in five genes in the revised International Prognostic Scoring 
System can improve risk stratification in the patients with myelodysplastic syndrome. Blood Cancer J 2018, 8(4):39.

13. Alhan C, Westers TM, Cremers EM, Cali C, Witte BI, Ossenkoppele GJ, van de Loosdrecht AA: The myelodysplastic syndromes flow cytometric score: a three-parameter prognostic flow cytometric scoring system. Leukemia 2016, 30(3):658-665.

14. Hainer SJ, Gu W, Carone BR, Landry BD, Rando OJ, Mello CC, Fazzio TG: Suppression of pervasive noncoding transcription in embryonic stem cells by esBAF. Genes Dev 2015, 29(4):362-378.

15. Spornraft M, Kirchner B, Pfaffl MW, Riedmaier I: Comparison of the miRNome and piRNome of bovine blood and plasma by small RNA sequencing. Biotechnol Lett 2015, 37(6):1165-1176.

16. Fatica A, Bozzoni I: Long non-coding RNAs: new players in cell differentiation and development. Nat Rev Genet 2014, 15(1):7-21.

17. Kung JT, Colognori D, Lee JT: Long noncoding RNAs: past, present, and future. Genetics 2013, 193(3):651-669.

18. Zhang X, Lian Z, Padden C, Gerstein MB, Rozowsky J, Snyder M, Gingeras TR, Kapranov P, Weissman SM, Newburger PE: A myelopoiesis-associated regulatory intergenic noncoding RNA transcript within the human HOXA cluster. Blood 2009, 113(11):2526-2534.

19. Zeng $C, X u Y, X u L, Y u X$, Cheng J, Yang L, Chen S, Li Y: Inhibition of long non-coding RNA NEAT1 impairs myeloid differentiation in acute promyelocytic leukemia cells. BMC Cancer 2014, 14:693.

20. Yildirim E, Kirby JE, Brown DE, Mercier FE, Sadreyev RI, Scadden DT, Lee JT: Xist RNA is a potent suppressor of hematologic cancer in mice. Cell 2013, 152(4):727-742.

21. Rodriguez-Malave NI, Rao DS: Long noncoding RNAs in hematopoietic malignancies. Brief Funct Genomics 2016, 15(3):227-238.

22. Zhang $X$, Rice $K$, Wang $Y$, Chen $W$, Zhong $Y$, Nakayama $Y$, Zhou $Y$, Klibanski A: Maternally expressed gene 3 (MEG3) noncoding ribonucleic acid: isoform structure, expression, and functions. Endocrinology 2010, 151(3):939-947.

23. You D, Wang D, Liu P, Chu Y, Zhang X, Ding X, Li X, Mao T, Jing X, Tian Z et al: MicroRNA-498 inhibits the proliferation, migration and invasion of gastric cancer through targeting BMI-1 and suppressing AKT pathway. Hum Cell 2020, 33(2):366-376.

24. Zhang S, Zhang $X$, Sun $Q$, Zhuang $C$, Li G, Sun L, Wang H: LncRNA NR2F2-AS1 promotes tumourigenesis through modulating BMI1 expression by targeting miR-320b in non-small cell lung cancer. J Cell Mol Med 2019, 23(3):2001-2011.

25. Fang J, Chen W, Meng XL: LncRNA CASC9 Suppressed the Apoptosis of Gastric Cancer Cells through Regulating BMI1. Pathol Oncol Res 2019.

26. Liu G, Wang L, Han H, Li Y, Lu S, Li T, Cheng C: LncRNA ZFAS1 promotes growth and metastasis by regulating BMI1 and ZEB2 in osteosarcoma. Am J Cancer Res 2017, 7(7):1450-1462.

27. Mihara K, Chowdhury M, Nakaju N, Hidani S, Ihara A, Hyodo H, Yasunaga S, Takihara Y, Kimura $\mathrm{A}: \mathrm{Bmi}-1$ is useful as a novel molecular marker for predicting progression of myelodysplastic syndrome and patient prognosis. Blood 2006, 107(1):305-308.

28. Petrov VN, Isaeva EV, Ulyanenko SE, Beketov EE, Yatsenko EM, Sayapina EV, Lepekhina LA, Nasedkina NV, Grivtsova LY, Kaprin AD: In Vivo Effects of Human Bone Marrow Mesenchymal 
Stromal Cells on the Development of Experimental B16 Melanoma in Mice. Bull Exp Biol Med 2020.

29. Gomez-Barrena E, Padilla-Eguiluz N, Rosset P, Gebhard F, Hernigou P, Baldini N, Rouard H, Sensebe L, Gonzalo-Daganzo RM, Giordano $R$ et al: Early efficacy evaluation of mesenchymal stromal cells (MSC) combined to biomaterials to treat long bone non-unions. Injury 2020.

30. Yagura K, Ohtaki H, Tsumuraya T, Sato A, Miyamoto K, Kawada N, Suzuki K, Nakamura M, Kanzaki K, Dohi K et al: The enhancement of CCL2 and CCL5 by human bone marrow-derived mesenchymal stem/stromal cells might contribute to inflammatory suppression and axonal extension after spinal cord injury. PLOS One 2020, 15(3):e0230080.

31. Shang Z, Zhao J, Zhang Q, Cao C, Tian S, Zhang K, Liu L, Shi L, Yu N, Yang S: USP9X-mediated deubiquitination of B-cell CLL/lymphoma 9 potentiates Wnt signaling and promotes breast carcinogenesis. J Biol Chem 2019, 294(25):9844-9857.

32. Zhang $H$, Yi X, Sun $X$, Yin N, Shi B, Wu H, Wang D, Wu G, Shang Y: Differential gene regulation by the SRC family of coactivators. Genes Dev 2004, 18(14):1753-1765.

33. Khawar MB, Mehmood R, Abbasi MH, Sheikh N: Multifactorial role of long non-coding RNAs (LncRNAs) in hematopoiesis. Front Biosci (Schol Ed) 2018, 10:119-126.

34. Cheng $H$, Huang $C M$, Wang $Y$, Hu XX, Xu XQ, Song XM, Tang GS, Chen L, Yang JM: Microarray profiling and co-expression network analysis of the IncRNAs and mRNAs associated with acute leukemia in adults. Molecular bioSystems 2017, 13(6):1102-1108.

35. Bracken AP, Kleine-Kohlbrecher D, Dietrich N, Pasini D, Gargiulo G, Beekman C, Theilgaard-Monch K, Minucci S, Porse BT, Marine JC et al: The Polycomb group proteins bind throughout the INK4A-ARF locus and are disassociated in senescent cells. Genes Dev 2007, 21(5):525-530.

36. Molofsky AV, Pardal R, Iwashita T, Park IK, Clarke MF, Morrison SJ: Bmi-1 dependence distinguishes neural stem cell self-renewal from progenitor proliferation. Nature 2003, 425(6961):962-967.

37. Jin HJ, Lee HJ, Heo J, Lim J, Kim M, Kim MK, Nam HY, Hong GH, Cho YS, Choi SJ et al: Senescence-Associated MCP-1 Secretion Is Dependent on a Decline in BMI1 in Human Mesenchymal Stromal Cells. Antioxidants \& redox signaling 2016, 24(9):471-485.

38. Rizo A, Olthof S, Han L, Vellenga E, de Haan G, Schuringa JJ: Repression of BMI1 in normal and leukemic human CD34(+) cells impairs self-renewal and induces apoptosis. Blood 2009, 114(8):1498-1505.

39. El-Sharnouby S, Redhouse J, White RA: Genome-wide and cell-specific epigenetic analysis challenges the role of polycomb in Drosophila spermatogenesis. PLOS genetics 2013, 9(10):e1003842.

40. Oguro H, Iwama A, Morita $\mathrm{Y}$, Kamijo $\mathrm{T}$, van Lohuizen $\mathrm{M}$, Nakauchi $\mathrm{H}$ : Differential impact of Ink4a and Arf on hematopoietic stem cells and their bone marrow microenvironment in Bmi1-deficient mice. The Journal of experimental medicine 2006, 203(10):2247-2253.

41. Merle M, Fischbacher D, Liepert A, Grabrucker C, Kroell T, Kremser A, Dreyssig J, Freudenreich $M$, Schuster F, Borkhardt A et al: Serum Chemokine-release Profiles in AML-patients Might Contribute to Predict the Clinical Course of the Disease. Immunological investigations 2019:1-21.

42. Yoshimura T: The production of monocyte chemoattractant protein-1 (MCP-1)/CCL2 in tumor microenvironments. Cytokine 2017, 98:71-78. 
43. Li X, Loberg R, Liao J, Ying C, Snyder LA, Pienta KJ, McCauley LK: A destructive cascade mediated by CCL2 facilitates prostate cancer growth in bone. Cancer Res 2009, 69(4):1685-1692.

44. Fujimoto H, Sangai T, Ishii G, Ikehara A, Nagashima T, Miyazaki M, Ochiai A: Stromal MCP-1 in mammary tumors induces tumor-associated macrophage infiltration and contributes to tumor progression. International journal of cancer 2009, 125(6):1276-1284.

45. Kitamura T, Qian BZ, Soong D, Cassetta L, Noy R, Sugano G, Kato Y, Li J, Pollard JW: CCL2-induced chemokine cascade promotes breast cancer metastasis by enhancing retention of metastasis-associated macrophages. The Journal of experimental medicine 2015, 212(7):1043-1059.

46. Wiseman BS, Werb Z: Stromal effects on mammary gland development and breast cancer. Science (New York, NY) 2002, 296(5570):1046-1049. 
A

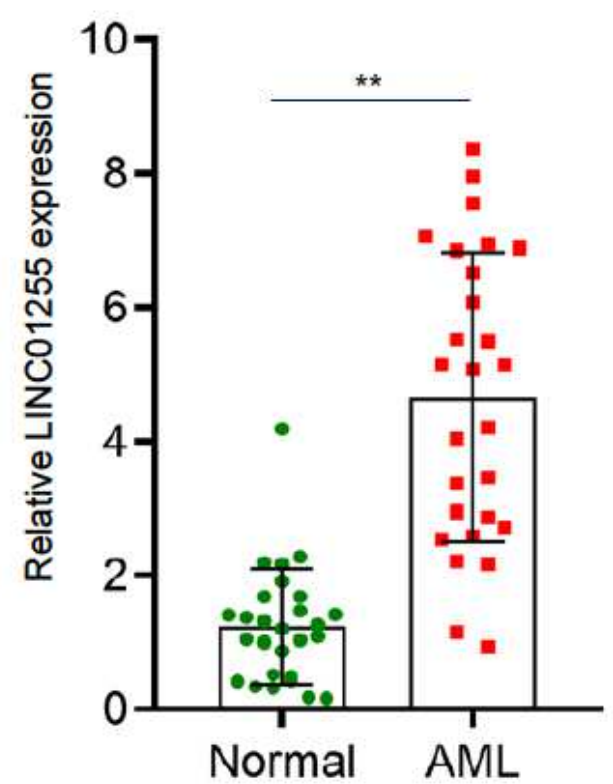

C

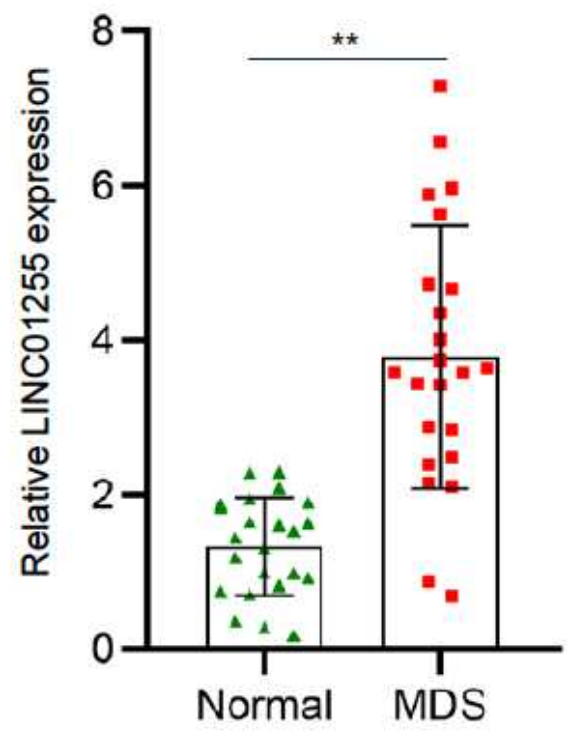

B
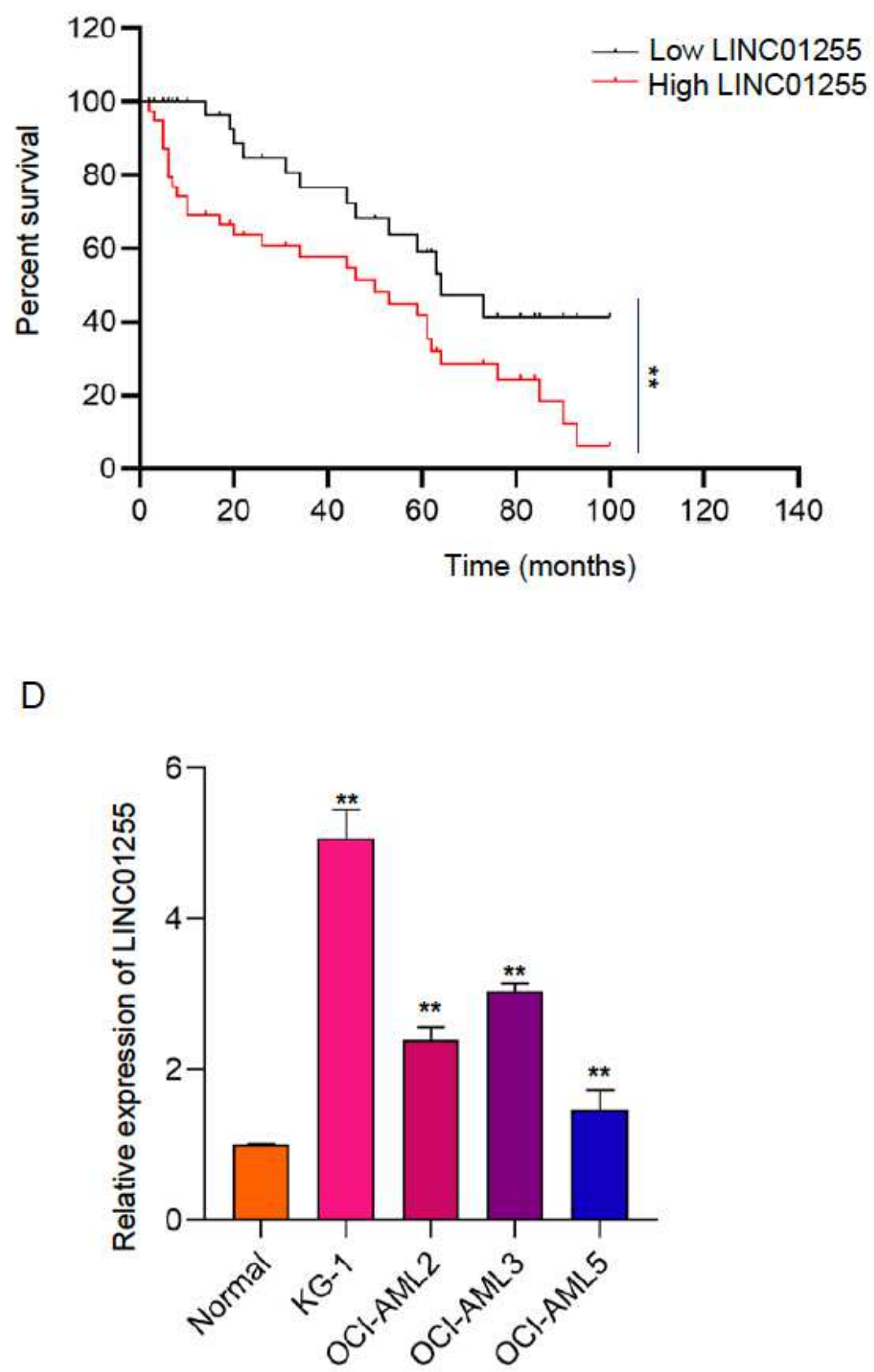

Figure 1

LncRNA LINC01255 Is highly-expressed in AML patients bone marrow cells, MDS-AML patients CD34+ cells and AML cell lines. (A) LncRNA LINC01255 is highly-expressed in bone marrow cells of AML patients compared with healthy controls. $n=27,{ }^{\star} P<0.01$, one-way analysis of variance (ANOVA) (B) 
AML patients with highly expressed LINC01255 have shorter overall survival compared to lower expression of LINC01255 $n=39, \star \star P<0.01$, two-way ANOVA. (C) LncRNA LINC01255 is highly-expressed in CD34+ cells of MDS patients compare to healthy body. $n=23, * \star P<0.01$, one-way analysis of variance (ANOVA). D ) LncRNA LINC01255 is highly-expressed in AML cell lines compare to normal bone marrow cells. ${ }^{*} \mathrm{P}<0.01$, one-way ANOVA .

A

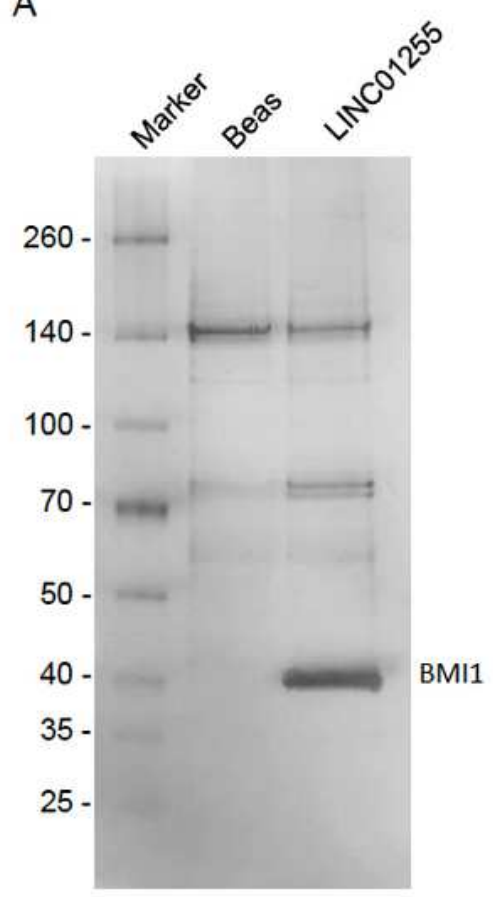

D
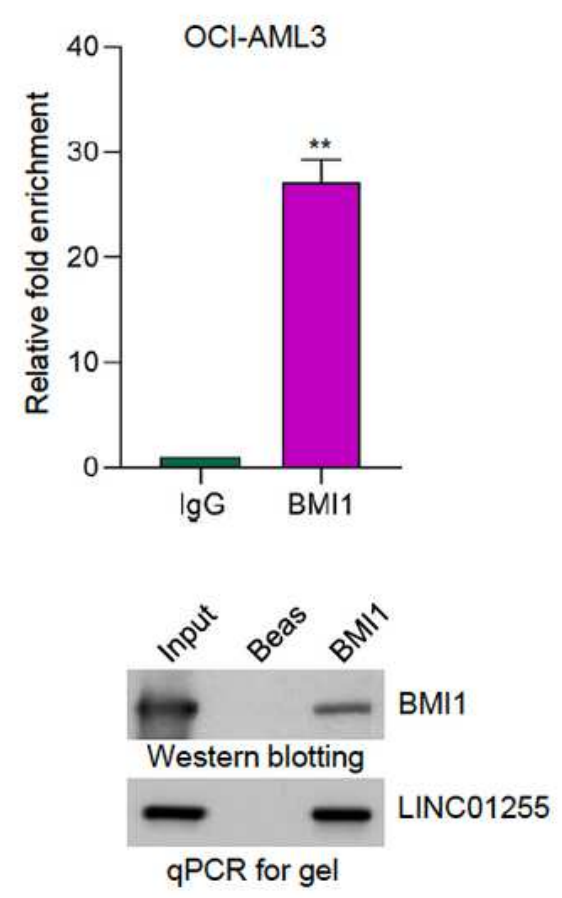

$\mathrm{E}$
B

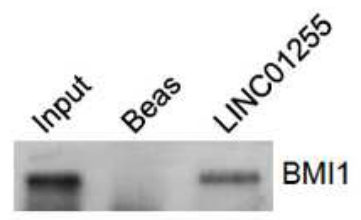

C

KG1
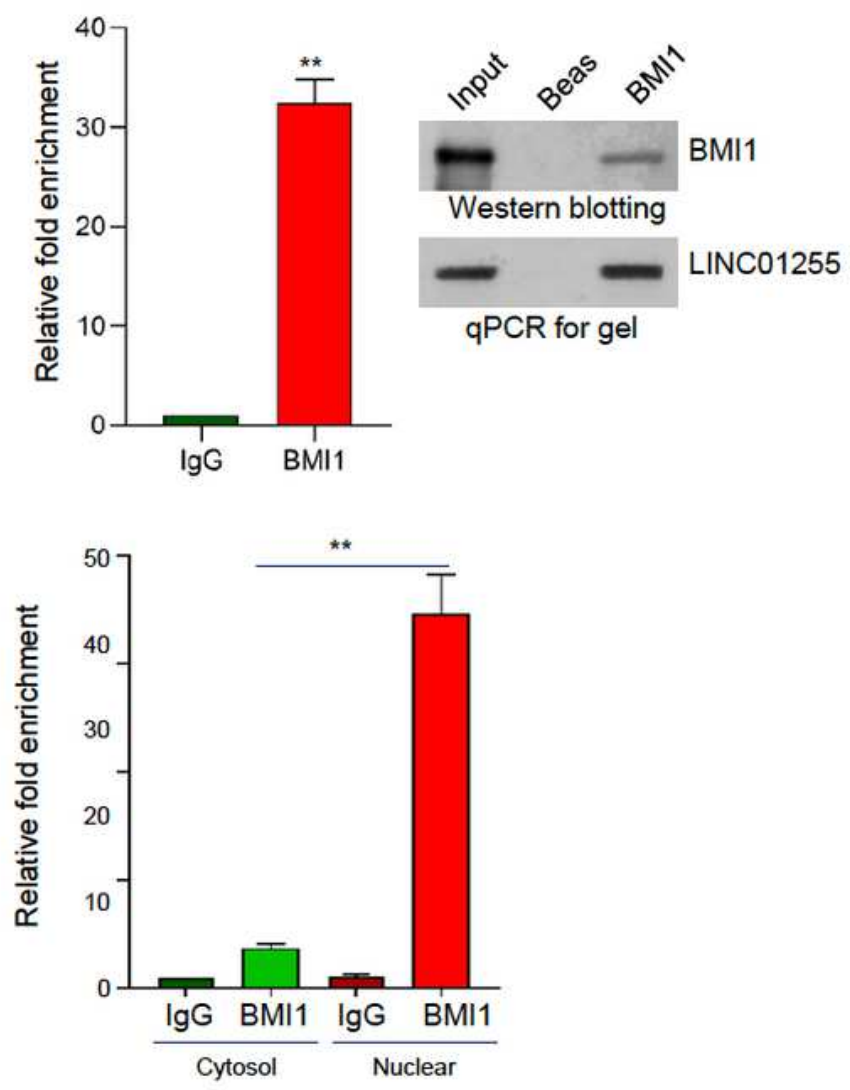

$\mathrm{F}$

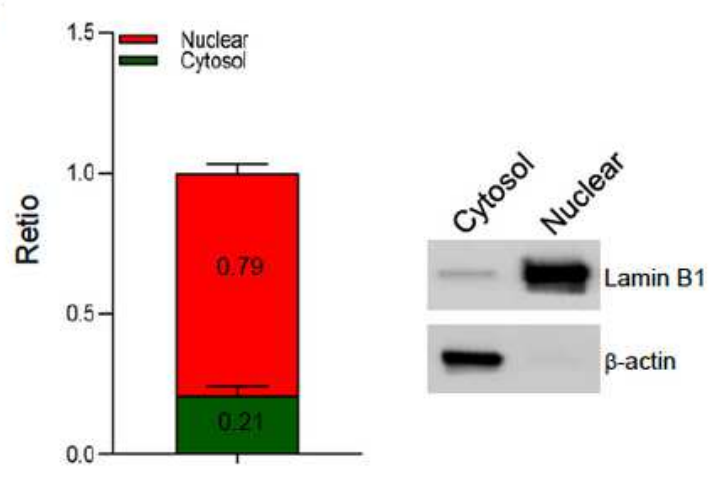

Figure 2 
LINC01255 Is Physically Associated with BMI1 . (A) RNA pull-down and Mass spectrometry analysis identified LINC01255-interacting proteins and visualized by silver staining on SDS-PAGE. Peptides information is showing at Supplementary Data 2 (B) LINC01255 RNA pull-down assay was examined by western blotting with antibody against BMI1 . (C) RNA immunoprecipitation (RIP) assays with anti-BMI1 antibody and followed by qRT-PCR analysis in KG1 cells. ${ }^{*} \mathrm{P}<0.01$, one-way ANOVA. (D) RNA immunoprecipitation (RIP) assays with anti-BMI1 antibody and followed by qRT-PCR analysis in OC1AML3 cells. ${ }^{* *} \mathrm{P}<0.01$, one-way ANOVA. (E) RNA immunoprecipitation (RIP) assays with anti-BMI1 antibody against different cellular components and followed by qRT-PCR assays in KG1 cells. ${ }^{*} P<0.01$, one-way ANOVA. (F) qRT-PCR analysis the expression level of LINC01255 in different cellular components. 

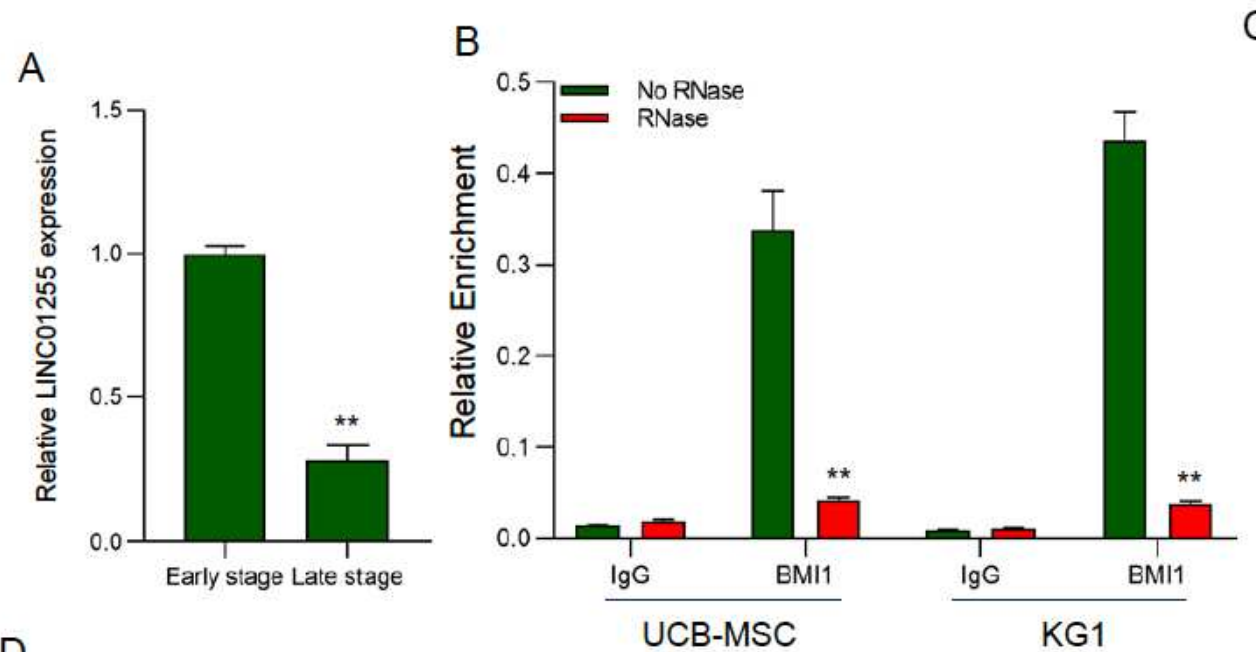

C

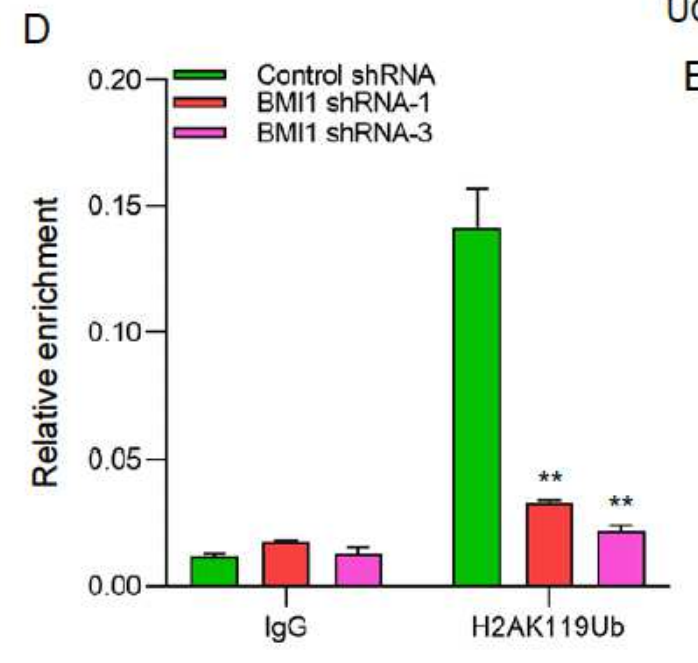

$\mathrm{E}$
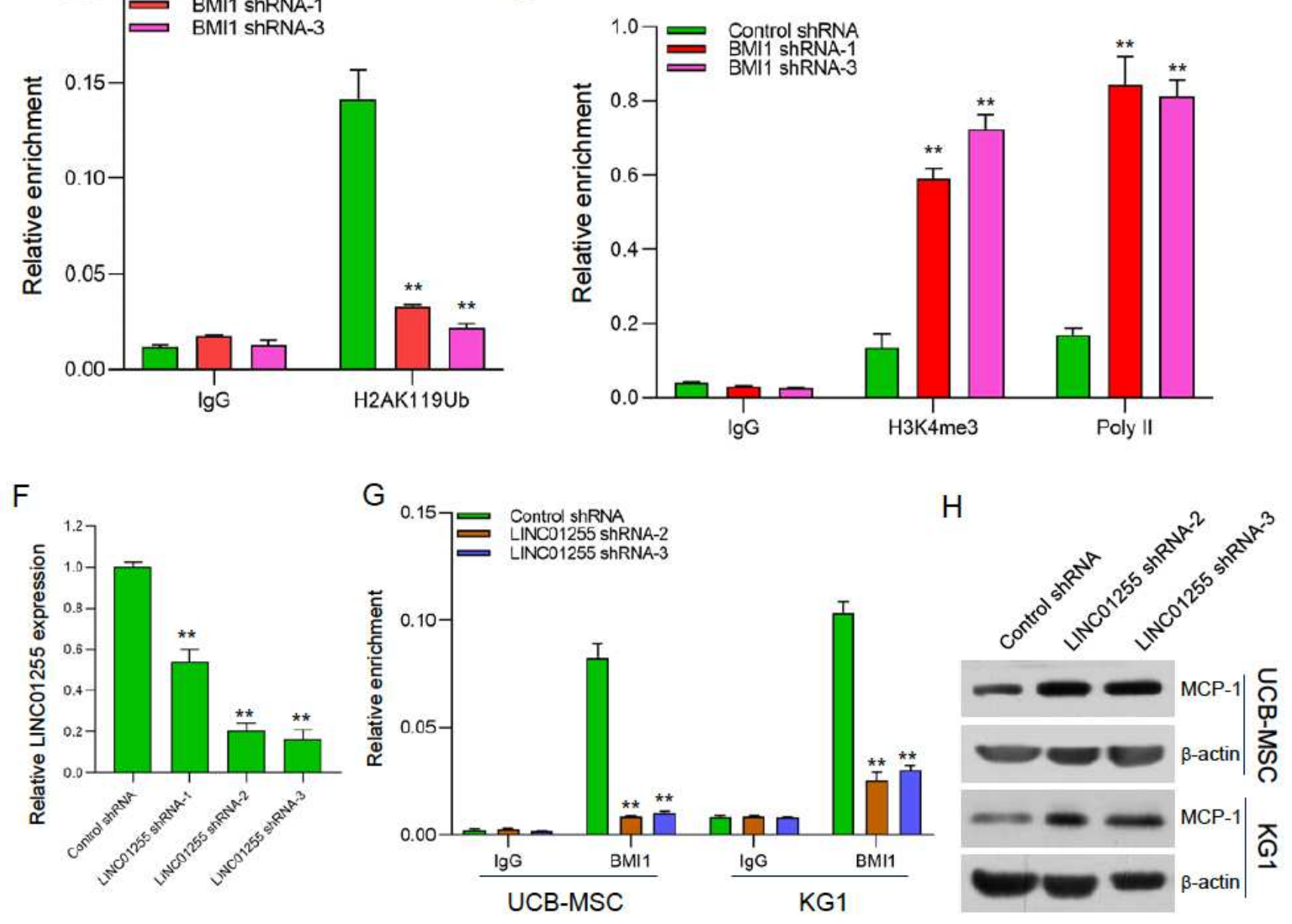

\section{Figure 3}

LINC01255 associated with BMI1 to repress the transcription of MCP-1 (A) qRT-PCR analysis the expression level of LINC01255 in senescence early and late stage of UCB-MSC cells. ${ }^{\star *} P<0.01$, one-way ANOVA (B) Chromatin immunoprecipitation (ChIP) analysis the binding ability of BMI1 at the promoter of MCP-1 promoter locus in early stage of UCB-MSC senescence and KG1 cells in absence RNAse or not . ${ }^{* * P}<0.01$, one-way ANOVA . (C) Western blotting of knockdown BMI1 through shRNAs in KG1 cells. (D) 
ChIP analysis the level of H2AK119Ub modification on the promoter of MCP-1 under knockdown BMI1. $\star * P<0.01$, one-way ANOVA. (E) ChIP analysis the level of H3K4me3 modification and binding of polymerase II on the promoter of MCP-1 under knockdown BMI1. ${ }^{*} \mathrm{P}<0.01$, one-way ANOVA .(F) qRT-PCR analysis the expression level of knockdown LINC01255 through shRNAs in KG1 cells . (G) ChIP analysis the binding ability of BMI1 at the promoter of MCP-1 promoter locus in early stage of UCB-MSC senescence and KG1 cells under knockdown LINC01255. ** $P<0$.01, one-way ANOVA . (H) Western blotting analysis the expression of BMI1 under knockdown LINC01255 through shRNAs in early stage of UCB-MSC senescence and KG1 cells. 
A

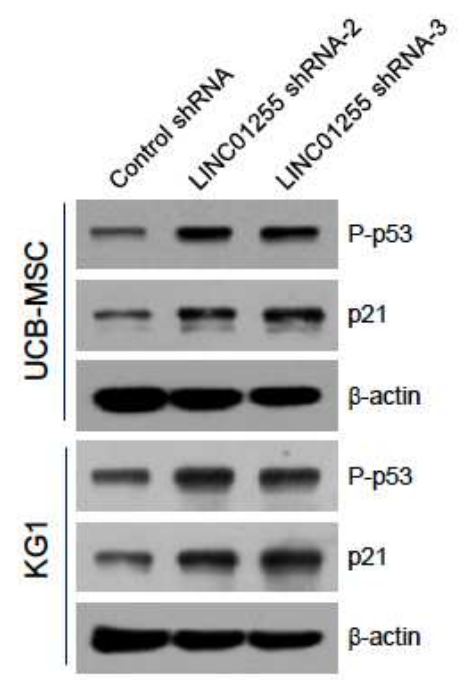

C

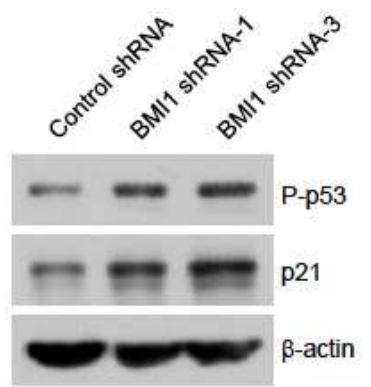

$\mathrm{E}$

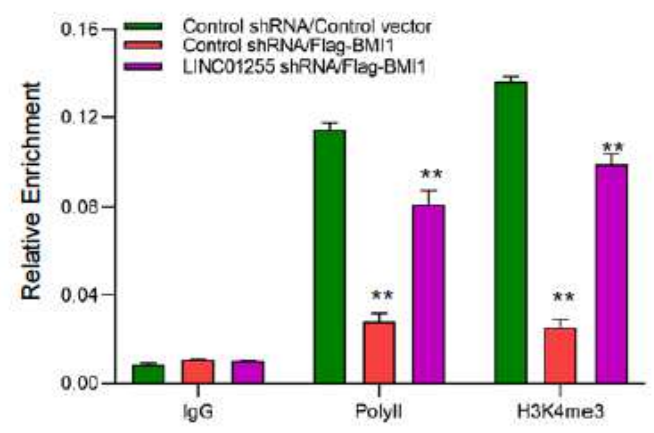

B

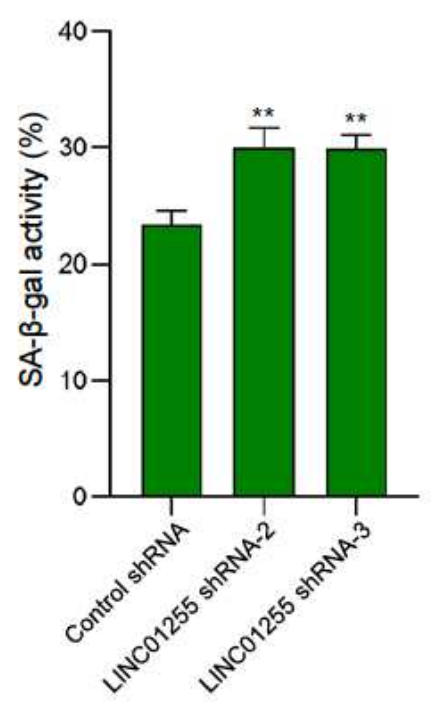

D

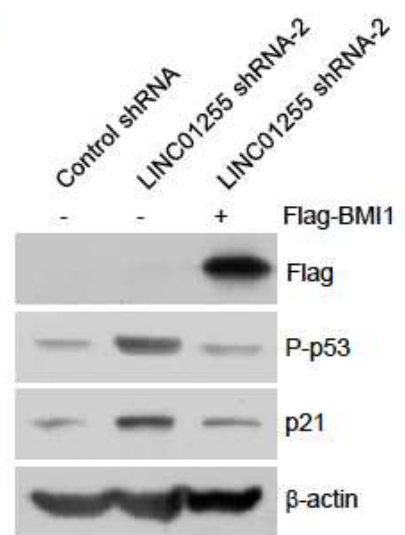

F

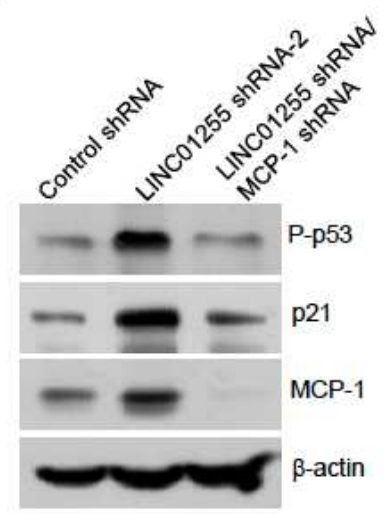

\section{Figure 4}

Down regulate LINC01255 active the p53 p21 signaling pathway through enhance expression of MCP-1. (A) UCB-MSC and KG1 cells were stably transcript shRNAs of LINC01255 and the expression of appreciate proteins analyzed by western blotting. (B) Knockdown LINC01255 increased the activity of SAB-gal. ${ }^{*} \mathrm{P}<0.01$, one-way ANOVA . (C) Knockdown BMI1 increased the p53-p21 pathway analyzed by western blotting. (D) Overexpression BMI1 under knockdown LINC01255 to analysis the expression of the 
proteins through western blotting. (E) ChIP analysis the level of H3K4me3 modification and binding of polymerase II on the promoter of MCP-1 under overexpression BMI1 and knockdown LINC01255 . ${ }^{*} \mathrm{P}<0.01$, one-way ANOVA . (F) Western analysis the expression of the proteins during knockdown LINC01255 and MCP-1 in the same time.

A

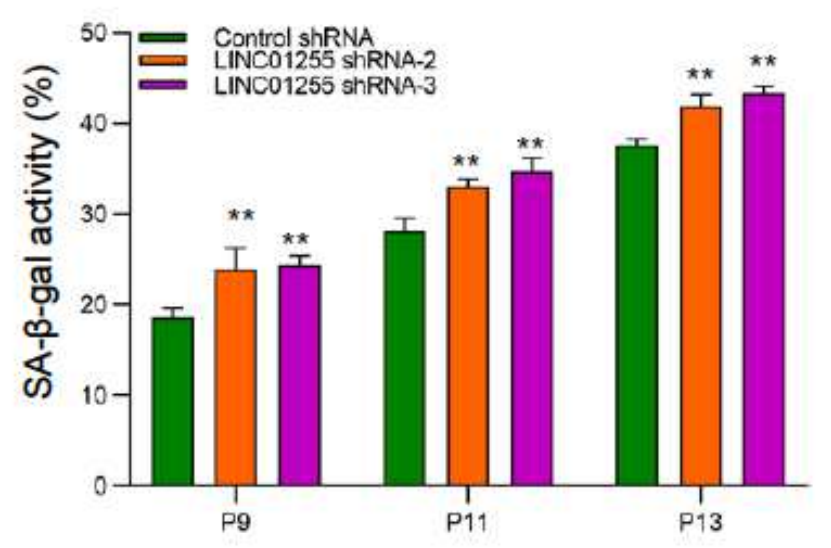

C

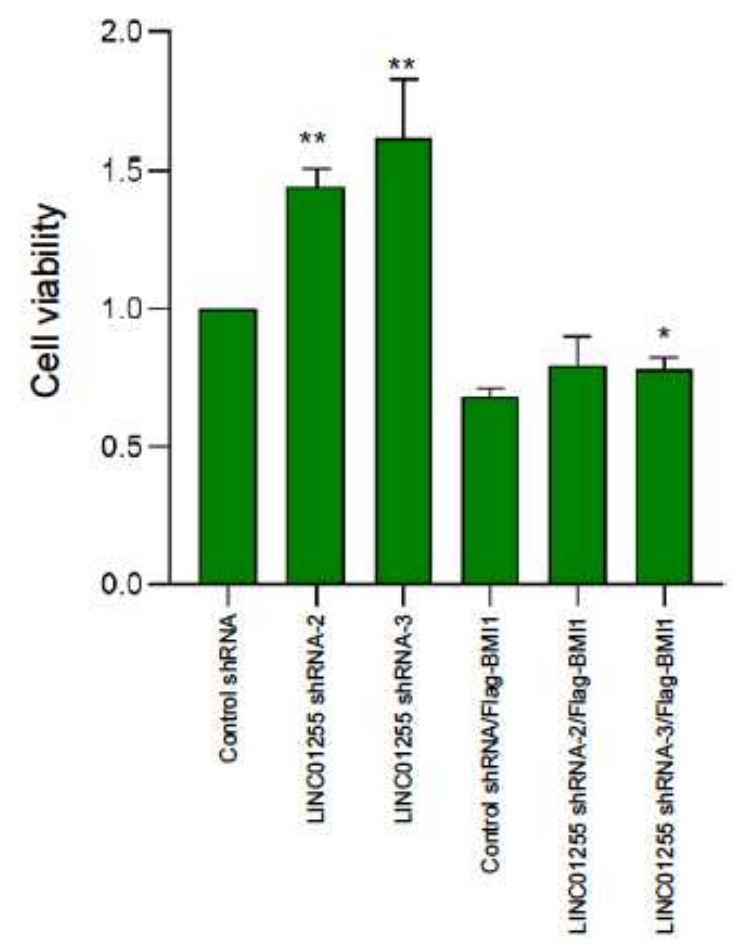

B
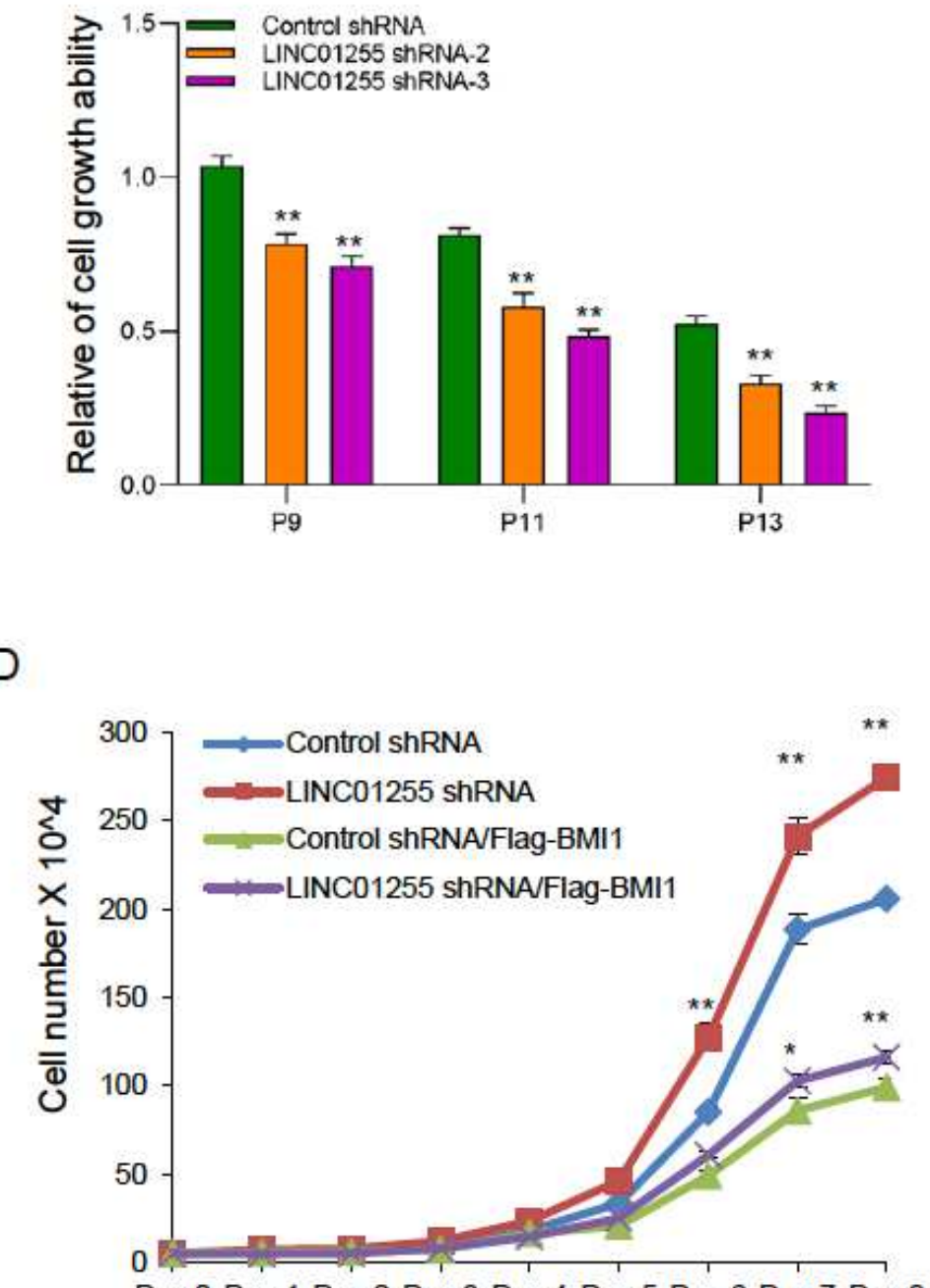

Day 0 Day 1 Day 2 Day 3 Day 4 Day 5 Day 6 Day 7 Day 8

Figure 5

BMI1/ LINC012 55 axis regulate senescence of HMC and proliferation of AML cell (A) The indicated passage $(P)$ number cells of UCB cells were transfect with shRNAs of LINC01255 and analyzed the SA- $\beta$ gal activity. ${ }^{\star *} P<0.01$, one-way ANOVA . (B) The indicated passage $(P)$ number cells of UCB cells were 
transfect with shRNAs of LINC01255 and analyzed the cell growth ability. ${ }^{* *} \mathrm{P}<0.01$, one-way ANOVA (C) KG1 cells were transfect the LINC012555 shRNAs or cotransfect with FLAG-BMI1 and analyzed the cell viability through CCK8 assays. ${ }^{*} P<0.01$, one-way ANOVA. (D) KG1 cells were transfect the LINC012555 shRNAs or cotransfect with FLAG-BMI1 and analyzed the cell proliferation. ${ }^{* *} \mathrm{P}<0.01$, one-way ANOVA

\section{Supplementary Files}

This is a list of supplementary files associated with this preprint. Click to download.

- SupplementalFile.pdf 